\title{
Design of crowning roller processing equipment and simulation research of key components
}

\author{
Meipeng Zhong \\ College of Mechanical and electrical Engineering, Jiaxing College, Jiaxing ,314001,China \\ zhongmeipeng@qq.com
}

Key word: Crowning roller , The edge stress , Processing equipment

Abstract: Crowning roller is widely applied in industrial applications today, large to the transmission system of the heavy body, small to the bearing parts.Crown roller with crown in order to eliminate $t$ he edge stress concentration phenomenon, so as to improve the service life of roller bearings.

In this paper, the design of processing equipment for crowning roller, and key parts of the equipment were checked.

Introduction:In the process of Cylindrical roller bearing operation, the ends of the roller will appear stress concentration and stress concentration, which effect on the bearing capacity and bearing fatigue life has an adverse [1].In order to prevent stress concentration in the end, a rectilinear trace raised some specific curve is usually fixed into the roller, namely the roller with a crown. Tiny on the surface of the roller crown [2], In addition to make the contact zones along the length direction of the stress distribution in uniform and reduce or eliminate the end stress concentration phenomenon, crown roller also make the bearing has a certain ability to resist axis deflection, which can significantly increase the service life of bearing.

Domestic and international industrial bearings are of cylindrical roller axial section shape design and technology realization method, long-term and in-depth research, great achievements have been gained. In order to protect their own interests, Foreign companies often made public only the research of sectional shape design, and implementation method of process, is almost all don't. Crown roller processing the new law, the author of this paper introduces the research and device [5], especially in centerless grinder and ultra lapping roller design problem, have been studied in detail.

\section{The crown roller processing principle and its equipment}

Through grinding method and through the ultra fine grinding method is used to approach to processing roller convexity, instead of straight generatrix roller to eliminate the edge effect and stress distribution of singular phenomenon, reducing the stress concentration, make the stress distribution is more reasonable. Through the method of grinding machining principle is shown in figure 1 [6].In centerless grinder, grinding wheel dressing by copying into inner concave surface, wheel dressing into outer convex surface (not necessarily in the centerless grinding machine), and adjust the plate face accordingly, in this way, roller to a curve path through the grinding zone, thereby gaining a crown profile. Throughout the ultra fine grinding method processing principle is shown in figure 2 [7]. Because of the guide roll along the axial processed into many type curve surface and roller with multiple curve between the two guide roller track, the roller is at the top of the crown after the oil-stone superfinishing. The curve is more in order to improve the efficiency of ultra lapping machining. Cylindrical roller superfinishing after the size of the crown and shape depends on the type of guide roll surface. 


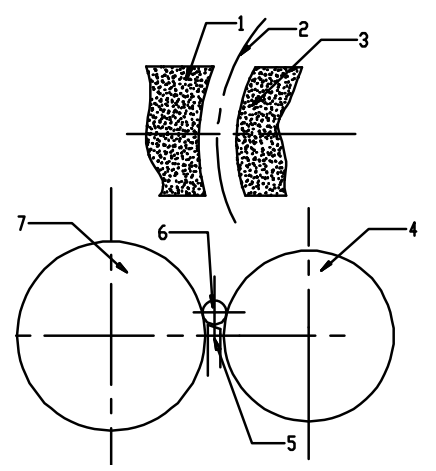

1 - grinding wheel profile curve;2 - roller path curve throughout;3 - type roller surface curve;4 - roller;5 - plate;6 - roller;7 - grinding wheel

Figure 1 roller crown through grinding principle

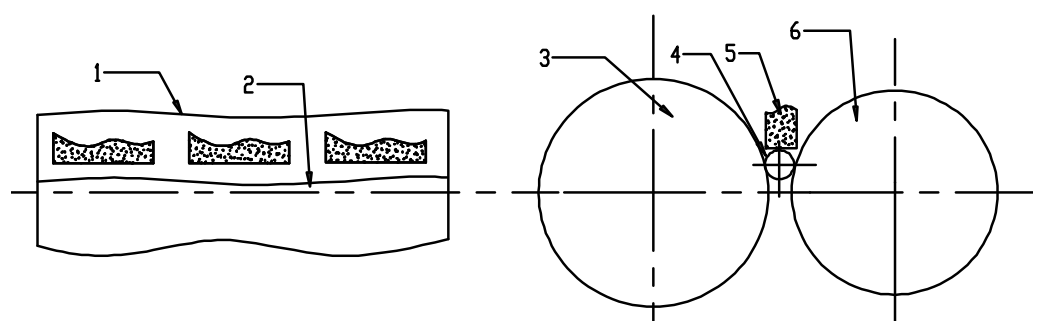

1 - guide roll profile curve;2 - roller path curve throughout; 3 after guide roller;4 - roller;5 - oil stone;6 - leading roll

Figure 2 roller crown through ultra lapping principle

Centerless grinding machine transmission diagram is shown in 3, now only introduce processing crown roller institutions, and do not concern feeding mechanism.

(1) The wheel rotation, 2 driven pulley through 1 wheel motor, the torque to 3 wheel spindle, grinding wheel spindle rotation, drive 11 wheel rotation.

(2) Guide wheel rotation, through 8 wheel motor driven 7 pulley, transfers the torque to 6 wheel drive shaft, through 5 worm and worm gear, the torque to the wheel spindle, 10 wheel is driven to rotate.

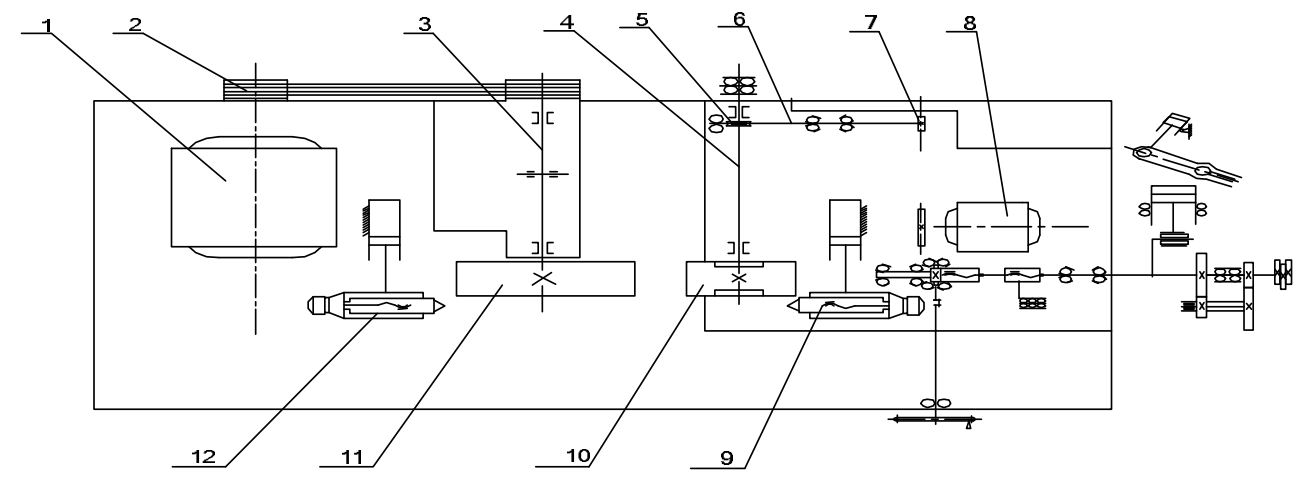

1 - motor 2 - grinding wheel belt transmission mechanism3 - grinding wheel spindle 4 - wheel spindle 5 - worm and worm wheel mechanism6 - wheel drive shaft7 - roller belt transmission mechanism8 wheel motor 9 wheel dresser 10 - wheel 11 - grinding wheel 12 - grinding wheel dresser

Figure 3 centerless grinding machine equipment diagram 


\section{Simulation study of key components}

Centerless grinding machine drive spindle should be no larger load and no big impact. According to the axial commonly used material mechanics performance contrast analysis to select the spindle of $40 \mathrm{Cr}$ steel, in order to ensure the surface with high hardness and tempering treatment. Table 1 is the material mechanics performance.

Table 1 main mechanical properties of materials

\begin{tabular}{|c|c|c|c|c|c|c|c|}
\hline material & $\begin{array}{l}\text { The } \\
\text { diamete } \\
\mathrm{r} \text { of the } \\
\text { blank } \\
(\mathrm{mm})\end{array}$ & $\begin{array}{l}\text { hardnes } \\
\text { s } \\
(\mathrm{HBS})\end{array}$ & $\begin{array}{l}\text { Tensile } \\
\text { strengt } \\
\text { h limit } \\
\text { ob }\end{array}$ & $\begin{array}{l}\text { Yield } \\
\text { strengt } \\
\text { h limit } \\
\text { os }\end{array}$ & $\begin{array}{l}\text { Bendin } \\
\mathrm{g} \\
\text { fatigue } \\
\text { limit } \\
\sigma-1\end{array}$ & $\begin{array}{l}\text { Shear } \\
\text { fatigue } \\
\text { limit } \\
\tau-1\end{array}$ & 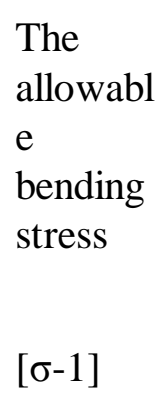 \\
\hline $40 \mathrm{Cr}$ & $20 \sim 100$ & $\begin{array}{l}241 \sim 28 \\
6\end{array}$ & $\begin{array}{l}735 \sim 68 \\
5\end{array}$ & $\begin{array}{l}540 \sim 49 \\
0\end{array}$ & $\begin{array}{l}355 \sim 35 \\
5\end{array}$ & $\begin{array}{l}200 \sim 18 \\
5\end{array}$ & 70 \\
\hline
\end{tabular}

The three-dimensional model of the shaft model was established based on solidworks, number of $40 \mathrm{Cr}$ steel material. Table 3-17 for the model properties. Must carry on the simulation, the static stress analysis of the torsional strength, must exert appropriate constraints, constraints, more reasonable simulation results more close to the actual situation. Transmission shaft of the constraint and load as shown in figure 4, add to them the bearings on both ends of the constraints, respectively corresponding to exert $M=100 \mathrm{n}$. M of torque. The structure of the transmission shaft is simple, the geometry is not great . In order to get higher reliability of analysis results, discretization of the unit can be smaller. figure 5 is the shaft after discretization.

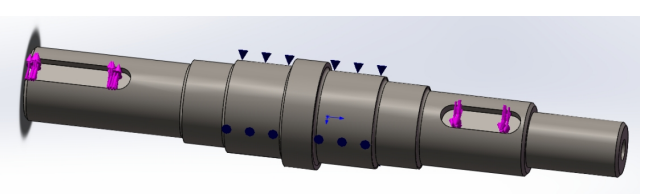

Figure 4 constraints load

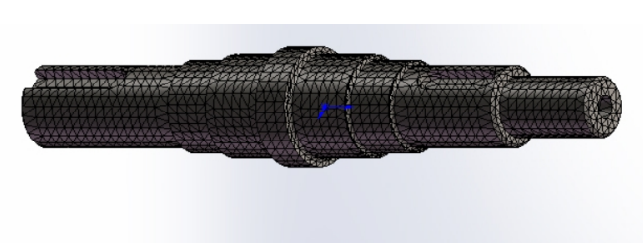

Figure 5 axis discretization

\section{The simulation results of key components}

On the basis of the modeling and meshing, has carried on the stress, strain and displacement to weeks, safety coefficient and fatigue check, such as design insight into the simulation. Strain, axial intensity static stress and safety coefficient of the figure 6,7 , and 8 , respectively. 

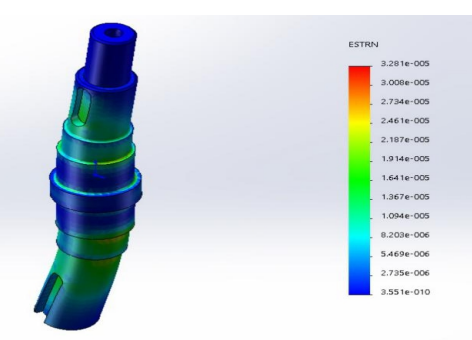
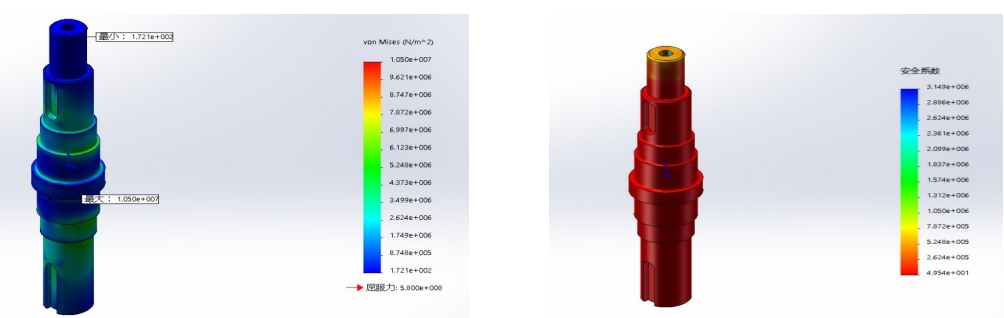

Figure 6 strain diagram Figure 7 axial intensity of static stress Figure 8 safety coefficient

Strain diagram can be seen from the figure 6, the simulation of the deformation ratio of 3571.3 , the maximum strain can be observed in excessive shaft, and the bilateral symmetry. This is mounted on the shaft bearing shaft fixed on the body, for the steps in strain is larger, the minimum strain for mm shaft, maximum strain for mm. As can be seen from the figure 7, the minimum stress of shaft is $1.721 \mathrm{MPa}$, the maximum stress of $10.50 \mathrm{MPa}$. According to mechanical design manual, comply with the design requirements.

Can be seen from the figure 8 minimum safety coefficient is 49.54 , and the shaft overall safety coefficient of uniform distribution.

\section{The conclusion}

Crown roller to crown the performance and life of roller bearings play a crucial role. The crown roller precision was solved by the design of crown roller equipment, this paper analyzes crown roller centerless grinding principle, the equipment was designed. The simulation research of its axis. Laid a theoretical basis for making crown roller gear.

\section{Acknowledgements}

The research work is supported by the natural science foundation of Zhejiang Province (LY14E050021), Public welfare projects of Zhejiang province (2015C31071).

\section{References}

[1] He Jiaqun. Dealing with the relation between five, promote the scientific development of bearing industry in China [J]. Journal of bearing, 2012, 2:1-5.

[2] Yang Xiaowei. Machine tool spindle bearing the latest technology [J]. Journal of bearing, 2010, $1: 22-25$.

[3] Ma Yaliang, Chen Renzhu compiled. Bearing manufacturing technology [M]. Beijing: tsinghua university press, 2008, 10.

[4] N. Umehara, R. Komanduri. Magnetic fluid grinding of HIP-Si3N4 rollers[J]. Wear, 1996, 192: 85-93.

[5]M. Raghumandan, A. Noori-Khajavi, N. Umehara, R, Komanduri. Magnetic float polishing of advanced ceramics[J].Trans ASME, J. of Manuf. Sci. and Eng., 1996, 119: 521-528.

[6] high as bin, Ding Haishan. Roller convexity processing technology present situation and development trend of [J]. Journal of bearing, 2003, 3-37.

[7] M. Raghunandan, R. Komanduri. Finishing of silicon nitride balls for high-speed bearing applications[J]. Trans. ASME J. Manf. Sci. and Eng, 1998,120:376-386. 